\title{
Gender and gender role differences in student- teachers' commitment to teaching
}

\author{
Ikupa Moses ${ }^{1,2} \cdot$ Wilfried F. Admiraal ${ }^{1}$ • \\ Amanda K. Berry ${ }^{3}$
}

Received: 2 June 2015/ Accepted: 17 April 2016/Published online: 13 May 2016

(C) The Author(s) 2016. This article is published with open access at Springerlink.com

\begin{abstract}
Low commitment to teaching amongst teachers is a problem facing the teaching profession in many countries. Gender might be an important factor in explaining what kinds of prospective teachers are attracted to teaching. This empirical study examined the relationship between student-teachers' gender, gender roles and commitment to teaching within the context of a large, university-based teacher education program in Tanzania. A self-report questionnaire was administered, comprising commitment to teaching items, gender as a demographic variable and items from Bem sex role inventory (BSRI). Cluster analysis on the masculine and feminine scale of the BSRI indicated three clusters: (1) highly androgynous students with high scores on both masculine and feminine scales, (2) medium androgynous students with relatively high scores on both masculine and feminine scales, and (3) low androgynous students with low scores in relation to the other two groups on both masculine and feminine scales of the BSRI. More female than male student-teachers reported to be highly androgynous. Covariance analysis showed that gender roles were significantly related to commitment to teaching and to intention to enter the teaching profession. Highly androgynous student-teachers reported significantly more commitment to teaching and higher intentions to enter the teaching profession compared to medium and low androgynous studentteachers. No significant relationships were found between gender, on the one hand, and commitment to teaching and the intention to enter the teaching profession, on the other hand. Findings are discussed in the context of teacher and teacher education in Tanzania.
\end{abstract}

Ikupa Moses

i.moses@iclon.leidenuniv.nl; ikumoses@gmail.com

1 Leiden University, Leiden, The Netherlands

2 Dar es Salaam University College of Education, Dar es Salaam, Tanzania

3 Royal Melbourne Institute of Technology, Melbourne, VIC, Australia 
Keywords Gender - Gender role $\cdot$ Student-teachers · Commitment to teaching

\section{Introduction}

Teachers' commitment to teaching is widely researched all over the world because of its important contribution to a number of aspects in education. Studies elucidate that commitment to teaching influences student-teachers' intention to enter the teaching profession (Rots et al. 2010) as well as job satisfaction and retention in the profession (Billingsley 2004; Day et al. 2005; Hackett et al. 2001; Klassen and Chiu 2011; Tait 2008). Teachers' commitment is also understood to be an important factor influencing school students' motivation and performance (Reyes 1990; Rosenholtz 1989). However, despite the importance attached to teachers' commitment, the literature indicates that low commitment to teaching amongst teachers is a problem facing the profession in many countries. Commitment to teaching has been identified as an important variable in determining teacher attrition (cf. Billingsley 2004; Ruhland 2001, 2002; Tait 2008). Low commitment to teaching is reflected in high rates of teacher attrition which is a result of voluntary resignation, absenteeism and dissatisfied and demotivated teachers (Macdonald 1999; Mulkeen and CroweTaft 2010; Mulkeen et al. 2007).

Gender has been revealed as one of the antecedents for commitment to teaching, although studies are not conclusive. For instance, commitment and positive attitudes to the teaching profession were found to be higher among female teachers compared to male teachers (Ingersoll et al. 1997). Additionally, studies reveal that more female than male student-teachers show higher intentions to enter the teaching profession after graduation (Guarino et al. 2006; Rots et al. 2014). However, in the same study, Guarino et al. reported that female student-teachers showed higher attrition rates than males, and female in-service teachers were more likely to quit teaching compared to males. Moreover, Mulkeen et al. (2007) reported that female teachers were also less likely to work in remote areas compared to males.

In the current study, we sought to further investigate commitment to teaching by investigating the influence of gender-biological make up of a person as either male or female-and gender role-a set of expectations for behaving, thinking, and feeling defining masculine or feminine characteristics. Stereotypical gender roles identify masculine traits in terms of instrumental personality traits, such as independence, assertiveness and dominance, while feminine traits refer to expressive traits such as sensitivity, empathy and nurturing (Spence 1993). In some studies (e.g., Dinella et al. 2014; Weisgram et al. 2010) gender role is also denoted as sexrole identity, gender traits, gender stereotypes or sex-typed personality traits (masculinity and femininity). In this study, we use the term gender role to represent the same above-mentioned terms used in other studies. Research has identified both gender and gender role as important factors in predicting people's attraction to particular activities (Dinella et al. 2014; Lippa 1998; Weisgram et al. 2010). 


\section{Literature review}

\subsection{Gender, gender roles and occupations}

Gender difference in occupational interest has been an area of focus for many researchers. Gender has been identified as an important predictor of people's attraction to different activities and occupations (Holland 1997; Lippa 1998). Holland's theory of career choice using a Realistic, Investigative, Artistic, Social, Enterprising, Conventional (RIASEC) model asserts that females tend to be more interested in social and artistic occupations, such as teacher, social worker, painter, and writer than males who are inclined more towards realistic occupations such as mechanic, carpenter and engineer (Holland 1997). Furthermore, using a PeopleThings dimension, it is noted that on average, females tend to be more interested in people-oriented occupations, and on average, males tend to be more interested in things-oriented occupations (Lippa 1998).

Additionally, gender roles have been found to be an important factor in predicting young adults' career interests and expectations (Dinella et al. 2014; Weisgram et al. 2010). People tend to become interested in occupations that reflect their gender roles. For instance, Dinella et al. (2014) found that the more masculine characteristics that young adults had, the more interested they were in masculine careers such as engineer or mechanic and the less interested they were in feminine careers such as teacher or social worker.

\subsection{Teaching as a feminized profession}

In many countries, a female workforce dominates teaching particularly at early childhood and primary levels (Drudy 2008; Kelleher 2011). While this "feminization" of the teaching profession has been a long-term phenomenon in developed countries such as Brazil, Australia, Canada and United Kingdom, it is now becoming the trend in some developing countries also (Kelleher 2011). Internationally, there are two main causes for the feminization of the teaching profession. First, socio-economic developments have created job opportunities that activate more male workers to go after new jobs, either for better payment or just for interest and exploration, leaving more teaching job opportunities for women (Kelleher 2011). Added to this, traditional views regarding men as the main economic provider of the family means that some men choose not to enter teaching because the salary is too low (Kelleher 2011). Second, teaching as a feminized profession is associated with socially perceived gender roles that relate teaching to a mother's (nurturing and caring) roles (Drudy 2008). Stereotypically, teaching is said to be a woman's "mission", in her "God-given nature" and her "proper place in society" (Kelleher 2011).

The impact associated with the feminization of the teaching profession is a topic of discussion amongst researchers. Some claim that the feminization of teaching leads to a decline in educational quality (Songtao 2000), students' discipline problems (Haywood et al. 2005), and the reduced status of teaching as a profession [Organization of Economic Co-operation and Development (OECD) 2004]. For 
example, it is asserted that due to the feminization of teaching, boys in schools lack social role models and so feel less engaged and do not perform well (Driessen 2007; Songtao 2000). On the other hand, Griffiths (2006) and Drudy (2008) point out that there is little evidence to prove that boys need male teachers to achieve better or that boys need male role models to feel engaged. The teaching profession status argument is controversial. While some conclude that there is a correlation between the feminization of the teaching profession and the status of the teaching as a profession, counter-arguments assert that in some countries where teaching is highly feminized, such as Finland, Korea, Ireland and Cyprus, teachers enjoy high professional status, with strong competition for entry into teacher education (Kelleher 2011). Also, in developing countries where the teaching profession is not yet feminized, there is a low status of the profession (Kelleher 2011).

\subsection{Commitment to teaching}

According to Tyree (1996) commitment refers to a high level of attachment to someone or something in a social endeavour and can manifest itself in extra investment of personal resources such as time, money, or effort. Coladarci (1992) defines commitment to teaching as a teachers' psychological attachment to the teaching profession. Researchers identify different dimensions of commitment including strong identification with, extra involvement with, and strong loyalty to someone or something (Tyree 1996), and affective, continuance and normative commitment (Meyer et al. 1993). Rots et al. (2010) included intentions to enter teaching, as an indicator of commitment to teaching, to explain graduates' choice to enter the teaching profession. Different studies have established that commitment to teaching is affected by different antecedents including personal characteristics (e.g., age, gender, self-efficacy and background), working condition, job satisfaction, learning experiences both prior and during teacher education, and experience in the profession (Billingsley 2004; Day et al. 2005; Fresko et al. 1997; Rots et al. 2010).

\subsection{Relationship between gender and commitment to the teaching profession}

Research on commitment to teaching shows inconclusive findings regarding gender aspects. In an international review study by Guarino et al. (2006) commitment, positive attitudes to the teaching profession and intention to enter the teaching profession were found to be higher among female teachers compared to male teachers. In their study of Israeli pre-service and in-service teachers, Fresko et al. (1997) found higher levels of job satisfaction and positive attitudes towards the profession among females compared to males. Likewise, Maliki (2013) found that female student-teachers in Nigeria showed more positive attitudes towards the teaching profession than males, and in Belgium, more female than male studentteachers showed higher intentions to enter the teaching profession after graduation (Rots et al. 2014). Nevertheless, Guarino et al. (2006) identified higher attrition rates among female student-teachers and in-service teachers compared to males; Ingersoll (2001) found that male teachers were less likely to depart than were female teachers 
in the USA and Mulkeen et al. (2007) found that female teachers were less likely to work in remote areas than males in Sub-Saharan Africa. In Australia, Watt et al. (2007) identified that gender was not a relevant factor for commitment to continue in, or to leave, the teaching profession, while in Israel, Fresko et al. (1997) found that gender was only indirectly related to commitment. Given these varying findings, we (authors) became interested to further investigate the relationship between gender and commitment to teaching. In addition, we anticipated that one reason why the findings related to gender differences in commitment to teaching are inconclusive might be due to a difference in gender and gender roles. Therefore, we included in our study on commitment to teaching both gender and gender roles.

\subsection{The Tanzanian context}

\subsubsection{Teacher recruitment}

The Tanzanian Commission for Universities (TCU) controls admission into undergraduate teacher education. The minimum entry qualification is at least two A-level subjects that will be student-teachers' future teaching subjects. From 2004, the Tanzanian government committed to increase the training and recruitment of teachers in response to a serious teacher shortage and a rapid increase in school enrolments. Teacher recruitment in Tanzania is centralized and graduates can be posted anywhere in the country. The centralized system was introduced in order to redress inequalities in the deployment of teachers within the country (Bennel and Mukyanuzi 2005). Between 2004 and 2013 [United Republic of Tanzania (URT) 2014], the number of teachers increased by $55.9 \%$ at primary level, and $291.4 \%$ at secondary level. However, despite government efforts to recruit teachers, student-teachers tend to be uninterested in teaching and not genuinely committed to the profession. In fact, they select teaching as a last resort after missing out on enrolment in other courses (Kitta and Fussy 2013; Towse et al. 2002; Tungaraza 2012). Further, findings from these studies show that student-teachers with low commitment to teaching have no intention to enter the teaching profession, or they intend to leave it in the near future after being employed.

\subsubsection{Condition of the profession}

The majority of teachers in Tanzania have a very low commitment to the teaching profession (Bennell and Mukyanuzi 2005; Jonathan et al. 2013; Mkumbo 2012). The teaching profession in Tanzania is characterized by its low status, teachers who are dissatisfied and demotivated, and very high levels of absenteeism and attrition (Bennell and Mukyanuzi 2005; Davidson 2007; Mulkeen et al. 2007).

\section{The current study}

As previously stated, the international research literature reveals low commitment to teaching amongst teachers and domination of females in the teaching workforce. Similarly, in Tanzania, where the current study was conducted, teacher commitment 
is devastatingly low (Bennell and Mukyanuzi 2005; Jonathan et al. 2013; Mkumbo 2012). The teaching profession is in the process of becoming feminized, with women becoming the majority. For example, there were more women in the teaching workforce by 2013 at pre-primary and primary levels than men [70 and $52 \%$ respectively; the United Republic of Tanzania (URT) 2014]. Thus, this study aimed to investigate whether student-teachers' gender and gender roles are related to their commitment to teaching.

Three research questions guided the study:

1. What are student teachers' gender role types?

2. How do female and male student-teachers and student-teachers with different gender role types vary in their commitment to teaching?

3. How do female and male student-teachers and student-teachers with different gender role types vary in their intentions to enter the teaching profession?

\section{Methodology}

\subsection{Procedure and participants}

Research clearance was obtained from the University of Dar Es Salaam and the Dar Es Salaam University College of Education. The main researcher made arrangements with individual lecturers to use approximately $50 \mathrm{~min}$ of class time for administration of a questionnaire. After a clear explanation of the study objectives, confidentiality issues and assuring student teachers that the study is not going to affect any part of their life as participants, the researcher invited student teachers to participate in the study.

Participants included 3246 student teachers (33\% females, $67 \%$ males) enrolled in a 3 years bachelor level program leading to a qualification to teach in either secondary schools or teacher education colleges. The study was conducted in the academic year of 2013/2014 at The Dar Es Salaam University College of Education (DUCE) in Tanzania and included student teachers in their first, second, the beginning of their third year of study (all in 2014/2015), as well as the end of their third year (2013/2014). Participants were recruited from four different teacher education courses within the University, including Bachelor of Arts with Education (B.A.ED), Bachelor of Science with Education (B.Sc.ED), Bachelor of Education in Arts (B.ED Arts) and Bachelor of Education in Science (B.ED Sc.).

\subsection{Measures}

\subsubsection{Commitment to teaching}

Data were collected via the use of a questionnaire. Based on studies on commitment (e.g., Klassen and Chiu 2011; Meyer et al. 1993; Ware and Kitsantas 2007; Watt and Richardson 2007) we constructed a 'Commitment to Teaching Scale' (CTS) by 
detailed scrutiny of commitment variables, picking and modifying items that captured our study interest. The CTS consisted of 35 items referring to various aspects of commitment to teaching. All items were answered on a 5-point Likert type scale, with $1=$ not at all and $5=$ very much.

The 35 commitment items were subjected to an exploratory principle component factor analysis in order to determine the underlying factors. By using the varimax rotation method, in the first step, four factors were identified having all the negatively formulated items grouped together into one factor. In the second step, these four negatively formulated items (with negations or negative terms) were deleted and only three factors were identified. The three factor solutions indicated the directions of two main factors although many items double loaded with almost the same values. Therefore, we forced a two factor rotation as a third step. The factor solution showed two factors explaining $47 \%$ of the variance. In order to optimize the two factor solution, we further deleted 2 items. The final factor analysis consisted of two components, Commitment to the Teaching Profession (CP) - 15 items, and Commitment to Student Learning (CL) - 14 items, explaining 25 and $24 \%$ of the variance respectively. The $\mathrm{CP}$ sub scale included items such as, 'I feel happy about becoming a teacher' and 'I talk positively about the teaching profession' while example items forming the CL sub scale included items such as, 'I have the responsibility to make my major teaching subject interesting to my students' and 'I am determined to help students to perform their best in my major teaching subject'. Table 1 indicates the rotated factor loadings of the two components. Next, we performed reliability analyses of the two identified factors (CP and CL), the intention to enter into the teaching profession sub-scale and the identified covariates. In Table 2, we show the reliability along with other descriptive statistics.

\subsubsection{Intention to enter the teaching profession}

Related to commitment to teaching, we also measured intention to enter the teaching profession. The intention scale included three items: 'I am certain I will take up teaching after my graduation', 'I intend to teach for a reasonable period of time after my training' and 'I am sure I will take up teaching as soon as I graduate'. These items were answered on a 5-point Likert type scale, with $1=$ not at all and $5=$ very much, and formed a reliable scale (see Table 2 ).

\subsubsection{Gender and gender role}

In addition to background information such as age and gender, we collected data about student-teachers' gender roles using the Bem Sex Role Inventory (BSRI; Bem 1974). The BSRI has three separate sub scales: masculine, feminine and neutral items (used as a dummy). The shortened version of the BSRI consists of 30 personality characteristics (10 for each scale) on which respondents rated themselves on a 7-point Likert scale ranging from 1 (never or almost never true) to 7 (always or almost always true). We deleted three items from the masculine subscale based on the reliability analysis resulting in a reliable feminine and masculine 
Table 1 Factor loadings based on a principal component analyses with varimax rotation for 29 items of a commitment scale $(\mathrm{N}=3246)$

\begin{tabular}{|c|c|c|}
\hline & $\begin{array}{l}\text { Commitment to } \\
\text { the teaching } \\
\text { profession }(\mathrm{CP})\end{array}$ & $\begin{array}{l}\text { Commitment } \\
\text { to students' } \\
\text { learning (CL) }\end{array}$ \\
\hline Feel happy becoming a teacher & .786 & .344 \\
\hline Proud to tell others I am a teacher to be & .755 & .317 \\
\hline Feel responsible to continue in the profession & .732 & .330 \\
\hline Happy with the choice & .729 & \\
\hline Willing to take ups and downs of the teaching profession & 697 & .315 \\
\hline Teaching holds great personal meaning to me & .692 & .329 \\
\hline Feel guilty if leave the teaching profession & 680 & \\
\hline Teaching is an ideal profession for me & .672 & \\
\hline Enthusiastic about teaching & .667 & .367 \\
\hline Will regularly upgrade knowledge as a teacher & .586 & .449 \\
\hline Talk positively the teaching profession & .543 & .397 \\
\hline Costly to change decision to become a teacher & .527 & \\
\hline It would be inappropriate to leave teaching now & .524 & \\
\hline Difficult changing decision to become a teacher now & .440 & \\
\hline $\begin{array}{l}\text { Changing decision to become a teacher now would require } \\
\text { sacrifice }\end{array}$ & .358 & \\
\hline Responsible to make teaching subject interesting to students & & .747 \\
\hline Determined to help students perform their best & & .734 \\
\hline Believe can make all students learn & & .730 \\
\hline Willing to share experiences with colleagues & & .706 \\
\hline Believe have responsibility to do the best for every student & & 695 \\
\hline Willing to take courses to develop subject knowledge & & 655 \\
\hline Believe is responsible for students' performance & & 655 \\
\hline Like to teach major teaching subject & & .651 \\
\hline Willing to spend free time reading subject materials & .311 & 645 \\
\hline Responsible for all students & & 630 \\
\hline Willing to use free time to organize subject activities & .427 & .544 \\
\hline Like major subject & & .534 \\
\hline Feel important to improve teaching skills & .433 & .521 \\
\hline Believe never give up for students who have negative attitude & & .506 \\
\hline
\end{tabular}

Only factor loadings $>\mathrm{I} .30 \mathrm{l}$ are printed

sub-scale (see Table 2). Examples of personality characteristics items used are 'affectionate' and 'loves children' for the feminine sub-scale and 'independent' and 'strong personality' for the masculine sub-scale.

\subsubsection{Covariates}

The study included five covariates, which refer to personal, learned experience and environmental variables that could influence student-teachers' commitment to 
Table 2 Descriptive statistics for the two commitment to teaching factors, other dependent and independent variables and covariates used in analyses

\begin{tabular}{lccccc}
\hline & $\begin{array}{l}\text { Number of } \\
\text { items }\end{array}$ & Mean & SD & $\begin{array}{l}\text { Cronbach's } \\
\alpha\end{array}$ & N \\
\hline Gender & & & & & 1056 \\
Females & & & & 2184 \\
Males & & & & \\
Gender role & 10 & 6.26 & 0.89 & .91 & 3204 \\
BSRI feminine sub-scale & 7 & 6.02 & 0.89 & .73 & 3200 \\
BSRI masculine sub-scale & & & & & 3246 \\
Commitment to teaching & 15 & 3.68 & 0.90 & .91 & 3246 \\
Commitment to teaching profession & 14 & 4.40 & 0.67 & .91 & 3246 \\
Commitment to students' learning & 3 & 3.99 & 0.95 & .70 & 3246 \\
Intention to enter the profession & & & & & 3246 \\
Covariates & 17 & 2.84 & 0.60 & .73 & 3246 \\
Environment & 5 & 3.05 & 1.09 & .82 & 3240 \\
Teaching attitude & 4 & 4.05 & 0.88 & .70 & \\
Subject attitude & 12 & 4.39 & 0.68 & .92 & .82 \\
Self-efficacy & 9 & 3.95 & 0.80 & & \\
Satisfaction & & & & & \\
\hline
\end{tabular}

teaching. These covariates were addressed in the same questionnaire as commitment and the items were based on the work of, for example, Billingsley (2004), Day et al. (2005) and Fresko et al. (1997). For self-efficacy we adopted the Teachers' Sense of Efficacy Scale (TSES-short form) developed by Tschannen-Moran and Hoy (2001). We slightly modified the self-efficacy items which originally were in a question form to be in a statement form. All items were answered on a 5-point Likert type scale with $1=$ Not at all and $5=$ Very much. Descriptive statistics of these covariates are presented in Table 2. The five covariates were:

1. Environmental perception scale (ENVIRONMENT) with items such as 'I think that teaching offers a low salary', and 'I am willing to teach anywhere in my country'.

2. Learning experience teacher and teaching profession attitude scale (TEACHING ATTITUDE) with items such as 'I believe teaching is a high status occupation' and 'I believe that in society teaching is perceived as a professional occupation'.

3. Learning experience perception of subject attitude scale (SUBJECT ATTITUDE) with example items such as 'I believe that secondary school students perceive my major teaching subject as important', and 'I think it is important that my major teaching subject is taught in secondary schools'.

4. Satisfaction with the teacher education program scale (SATISFACTION), for example items such as 'I am happy with the way I am prepared to become a teacher' and 'I am satisfied with my teacher education training program'. 
5. Teacher self-efficacy scale (SELF-EFFICACY), for example items such as 'I think I can use a variety of assessment strategies' and 'I think I can motivate students who show low interest in schoolwork'.

\subsubsection{Analysis}

In order to obtain the student teachers' typology of gender role (research question 1) we performed cluster analysis on the masculine and feminine scale of the BSRI. In order to ascertain the optimal cluster analysis for our data, we used the Variance Ratio Criterion (VRC, see Calinski and Harabasz 1974). This criterion refers to the ratio of the 'within variance' (variance explained by the typology) and 'between variance', corrected for the number of clusters and responses. We evaluated all cluster analysis methods that are available in the SPSS package version 22, with $\mathrm{K}$-means with three clusters with the highest VRC-scores. In order to examine the relationship between gender, gender roles and commitment to teaching (research question 2), we performed multivariate analyses of covariance with gender and gender role as explanatory variables, the commitment scales as dependent variables and the five covariates. In order to examine the relationship between gender, gender roles and intentions to enter into the teaching profession (research question 3 ), we performed a two way analysis of covariance with gender and gender roles as explanatory variables, intention scale as dependent variable, and the five covariates.

\section{Results}

\subsection{Gender role types}

The final cluster analysis showed that three types of gender role could be distinguished. The first type was characterized by highly androgynous studentteachers who generally had very high scores on both the masculine and feminine scale of the BSRI $\left(\operatorname{Mean}_{\text {feminine }}=6.7\right.$ and masculine $\left.=6.6\right)$. The second type was characterised by medium androgynous student-teachers with a relatively high score on both masculine and feminine scales of the BSRI $\left(\mathrm{Mean}_{\mathrm{feminine}}=5.9\right.$ and masculine $=5.5$ ). The third type was characterized by low androgynous studentteachers with the lowest score in relation to the other two groups on both masculine and feminine scales of the BSRI $\left(\operatorname{Mean}_{\text {feminine }}=3.8\right.$ and masculine $\left.=4.0\right)$. The graphical representation of the gender role distributions along the masculine and feminine scale is shown in Fig. 1.

Moreover, by the use of cross tabulations, findings indicated statistically significant gender role differences between gender categories, year and program of study. The first type, highly androgynous student teachers, included significantly more females than males $\left[x^{2}(2, \mathrm{~N}=3194)=10.86, p=.004\right]$, significantly more first year student teachers than second or third year student-teachers $\left[x^{2}(6\right.$, $\mathrm{N}=3185)=56.11, p<.001]$, and significantly more student-teachers studying Arts subjects than student-teachers studying Science subjects $\left[x^{2} \quad(6\right.$, 


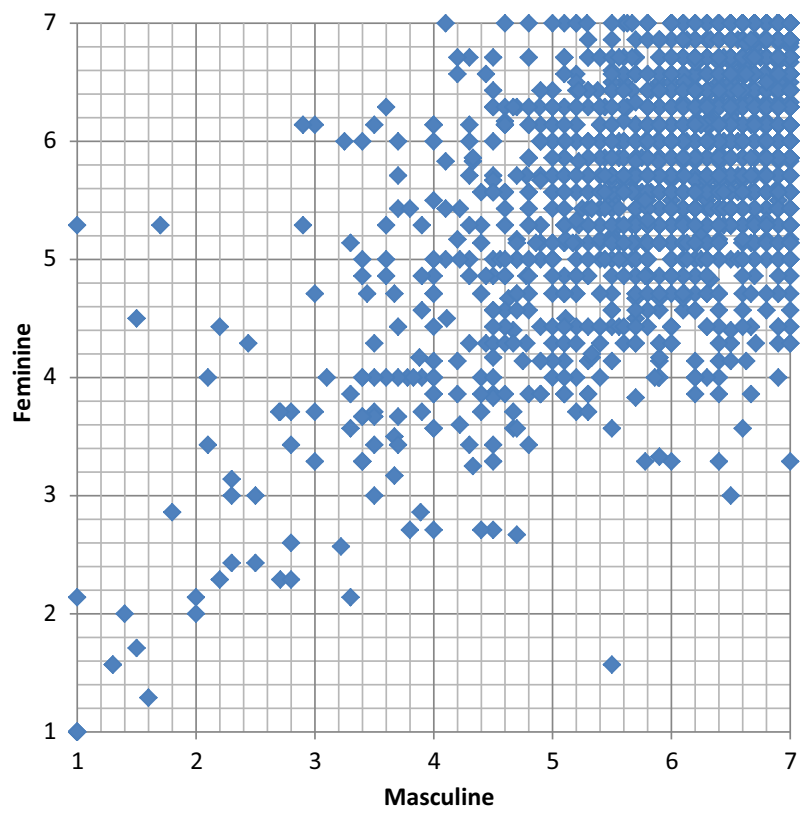

Fig. 1 Gender role distributions

$\mathrm{N}=3189)=45.26, p<.001]$. In Table 3, we summarize the descriptive statistics for the three gender role types.

\subsection{Relationship between gender, gender roles and commitment to teaching}

Both commitment scales [commitment to the teaching profession (CP) and commitment to students' learning (CL)] were significantly correlated $(r=0.70)$. Therefore, we performed multivariate analyses with the two dependent variables and covariates in the main analyses (MANCOVA). The descriptive statistics for each type are included in Table 4.

We found a statistically significant effect of gender role on student-teachers' commitment to teaching [Wilks' $\lambda(4,6358)=1.0 ; p<.001 ; \eta^{2}=.003$ ]. There was a significant relationship between gender role and $\mathrm{CP}[\mathrm{F}(2,3188)=5.0 ; p=.007$; $\left.\eta^{2}=.003\right]$ and between gender role and $\mathrm{CL}[\mathrm{F}(2,3188)=6.91 ; p=.001$; $\left.\eta^{2}=.004\right]$. All gender role types differ from each other significantly (Scheffé $p<.05)$ with the highly androgynous type reporting the highest CP and CL level and the low androgynous type the lowest. Both effects can be understood as small effects (cf. Cohen 1988). We found no significant effect of gender on studentteachers' commitment to teaching [Wilks' $\lambda(2,3177)=1.0 ; p=.23 ; \eta^{2}=.001$ ] and no interaction effect between gender and gender role [Wilks' $\lambda(4,6354)=1.0$; $p=.79]$. 


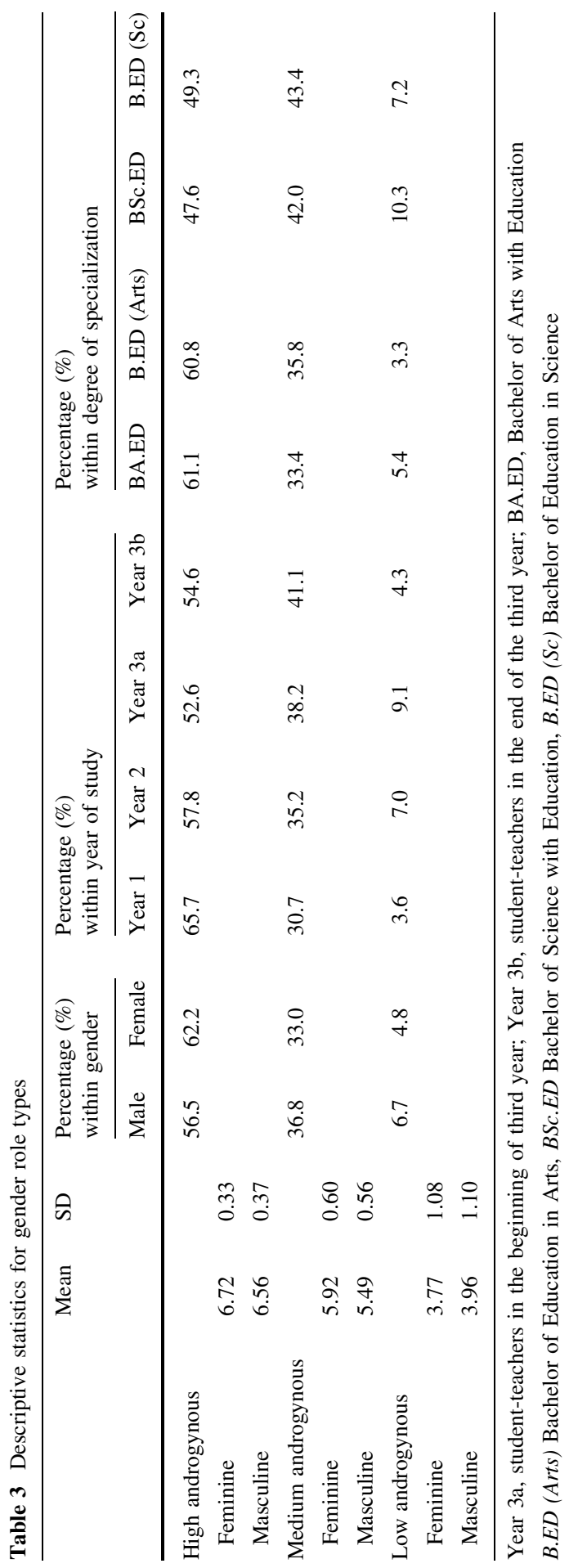


Table 4 Descriptive statistics of primary study variables

\begin{tabular}{|c|c|c|c|c|c|c|c|c|c|}
\hline & \multicolumn{3}{|c|}{$\begin{array}{l}\text { Commitment to teaching } \\
\text { profession }(\mathrm{CP})\end{array}$} & \multicolumn{3}{|c|}{$\begin{array}{l}\text { Commitment to student } \\
\text { learning }(\mathrm{CL})\end{array}$} & \multicolumn{3}{|c|}{$\begin{array}{l}\text { Intention to enter the } \\
\text { profession }\end{array}$} \\
\hline & Mean & SD & $\mathrm{N}$ & Mean & SD & $\mathrm{N}$ & Mean & SD & $\mathrm{N}$ \\
\hline \multicolumn{10}{|l|}{ Gender } \\
\hline Females & 3.80 & 0.85 & 1040 & 4.46 & 0.58 & 1040 & 4.07 & 0.89 & 1040 \\
\hline Males & 3.63 & 0.91 & 2149 & 4.37 & 0.70 & 2149 & 3.96 & 0.96 & 2149 \\
\hline \multicolumn{10}{|l|}{ Gender role type } \\
\hline High androgynous & 3.79 & 0.89 & 1861 & 4.50 & 0.62 & 1861 & 4.13 & 0.92 & 1861 \\
\hline Medium androgynous & 3.60 & 0.86 & 1135 & 4.33 & 0.63 & 1135 & 3.87 & 0.90 & 1135 \\
\hline Low androgynous & 3.12 & 0.93 & 193 & 3.83 & 0.91 & 193 & 3.42 & 1.11 & 193 \\
\hline
\end{tabular}

\subsection{Relationship between gender, gender roles and intentions to enter the teaching profession}

Findings from the analysis of covariance indicated a statistically significant relationship between gender roles and intention to enter the teaching profession $\left[\mathrm{F}(2,3188)=3.67 ; p=.026 ; \eta^{2}=.002\right]$. All gender role types differ from each other significantly (Scheffé $p<.05$ ) with the highly androgynous type showing the highest intentions to enter the teaching profession and the low androgynous type, the lowest. The effect can be understood as small effects (cf. Cohen 1988). No significant effect was found for gender $[\mathrm{F}(1,3188)=.56 ; p=.45]$ and for the interaction between gender and gender role $[\mathrm{F}(2,3188)=.19 ; p=.83]$. Table 4 shows the descriptive statistics of the studied variables.

\section{Discussion}

This study was guided by three main questions. Regarding the first question about student-teachers' gender role types, all participants reported high in both feminine and masculine characteristics, though in differing degrees. As such, cluster analyses identified three main categories of gender role amongst student teachers, including: highly androgynous, medium androgynous and low androgynous. The largest cluster was the highly androgynous, followed by the medium androgynous with very few clustered under the low androgynous type. Using Bem's categorisations, people scoring high in both feminine and masculine scale are labelled as androgynous (Bem 1974). Remarkably, our results showed only an androgynous category without a feminine or masculine cluster per se; results that may possibly be due to student-teachers' self-selection into teacher education and/or that studentteachers adopt different gender characteristics to fit the teaching job. The findings from this question might be useful for recruitment processes because, according to Bem, androgynous people have a broad range of behaviours that helps them to adapt to the situation as required. Furthermore, our analysis revealed that more female 
than male student-teachers, and more student-teachers studying Arts subjects than those studying Science subjects, could be identified as highly androgynous. This is not surprising, as Science is traditionally perceived as a masculine field (Vantieghem et al. 2014).

The second question of interest to this study geared towards understanding how female and male student-teachers and student-teachers with different gender role types vary in their commitment to teaching. We found significant effects of gender role type with the highly androgynous student teachers generally showing the highest commitment to the teaching profession and commitment to student learning. Although with a small effect size, the more androgynous the student teachers appeared to be, the more committed to teaching they were. From this point of view, we can comment that both feminine and masculine characteristics might be needed for the teaching profession. Moreover, unlike the review study by Guarino et al. (2006) and a Nigerian based study by Maliki (2013) in which gender was found as an important factor for commitment to teaching amongst student-teachers, this study did not find a significant relationship between gender and student-teachers' commitment to teaching. The difference may be due to the fact that the abovementioned studies only included gender and not gender roles. It is also important to note from this study that Tanzanian gendered socialization did not appear to have an influence on the findings.

Third, this study investigated how female and male student-teachers and student-teachers with different gender role types vary in their intentions to enter the teaching profession. Again, we found a positive relationship between gender roles and intentions to enter the teaching profession after graduation: The more androgynous the student teachers, the higher their intentions to enter teaching after graduation. In contrast to the findings of Guarino et al. (2006) and Rots et al. (2014), who found higher intentions to enter the teaching profession amongst female than male pre-service teachers, in this study gender was not found as an important predictor of student teachers' intentions to enter the teaching profession after graduation. Again the difference may be because of the inclusion of gender role as a variable in our study. Another reason may be related to differences in the levels of development between the countries of study, in this case less developed Tanzania and more developed countries in the other studies (USA and Belgium). In the less developed countries, there is less socio-economic development, so fewer job opportunities than in highly developed countries where, according to Kelleher (2011), socio-economic developments have created job opportunities that activate more male workers to go after new jobs, leaving teaching job opportunities to women.

\subsection{Limitations}

The use of the BSRI is criticised by some researchers in that the masculinity and femininity dimensions, which were supposed to be independent dimensions were proved not so. For example, investigation by Marsh and Myers (1986) indicated that masculinity and femininity are actually correlated mildly with each other. However, although the BRSI was developed in the 1970s and has been criticised in the 
literature, it is still used in recent studies (Borhart and Terrell 2014; Hunt et al. 2006; Rice 2006). So, we believe the BSRI is still a valid measurement of gender role. A further limitation is that these findings were obtained from one University College, which is a teacher education institution per se. It might be that our findings cannot be generalized to other colleges with mixed programs and other teacher education colleges of other qualifications levels in the country. The reasons for this could be that students of Universities with mixed programs are confronted with students of other programs which might influence their attitudes towards the teaching profession.

\section{Conclusion}

Gender role appeared to be an important factor for student-teachers' commitment to teaching although small effect sizes were observed. The reported small effect sizes indicate that there are other factors influencing student teachers' commitment and intention to join the profession that were beyond the scope of this research. However, gender as a variable, which has been used in many commitment studies, showed no effect in relation to commitment to teaching in this study. Thus we recommend that in order to understand the relationship between gender and student teachers' commitment to teaching, gender role should be included in future studies. Moreover, we suggest future studies could be conducted in different cultural contexts, with teacher education colleges at lower academic levels and universities with mixed programs in order to understand more fully the relationship between gender and teacher commitment. Finally, longitudinal studies could examine the development of gender role, commitment to teaching and its relationship, both among student-teachers and in-service teachers.

Acknowledgments This research was funded by the Netherlands Fellowship Program (NFP).

Open Access This article is distributed under the terms of the Creative Commons Attribution 4.0 International License (http://creativecommons.org/licenses/by/4.0/), which permits unrestricted use, distribution, and reproduction in any medium, provided you give appropriate credit to the original author(s) and the source, provide a link to the Creative Commons license, and indicate if changes were made.

\section{References}

Bem, S. L. (1974). The measurement of psychological androgyny. Journal of Consulting and Clinical Psychology, 42(2), 155-162.

Bennell, P., \& Mukyanuzi, F. (2005). Is there a teacher motivation crisis in Tanzania? Retrieved March 09, 2016, from http://www.eldis.org/vfile/upload/1/document/0709/teacher_motivation_tanzania. pdf.

Billingsley, B. S. (2004). Special education teacher retention and attrition: A critical analysis of the research literature. Journal of Special Education, 38(1), 39-55.

Borhart, H. M., \& Terrell, H. K. (2014). Perceptions of aggression are coloured by gender roles. The Psychological Record, 64(3), 441-445. 
Calinski, T., \& Harabasz, J. (1974). A dendrite method for cluster analysis. Communications in Statistics, 3(1), 1-27.

Cohen, J. (1988). Statistical power analysis for the behavioral sciences. Hillsdale, NJ: Erlbaum.

Coladarci, T. (1992). Teachers' sense of efficacy and commitment to teaching. The Journal of Experimental Education, 60(4), 323-337.

Davidson, E. (2007). The pivotal role of teacher motivation in Tanzanian education. The Educational Forum, 71(2), 157-166.

Day, C., Elliot, B., \& Kington, A. (2005). Reform, standards and teacher identity: Challenges of sustaining commitment. Teaching and Teacher Education, 21(5), 563-577.

Dinella, L. M., Fulcher, M., \& Weisgram, E. S. (2014). Sex-typed personality traits and gender identity as predictors of young adults' career interests. Archives of Sexual Behaviour, 43, 493-504.

Driessen, G. (2007). The feminization of primary education: The effects of teachers' sex on pupil achievements, attitude and behavior. International Review of Education, 53(2), 183-203.

Drudy, S. (2008). Gender balance/gender bias: The teaching profession and impact of feminisation. Gender and Education, 20, 309-323.

Fresko, B., Kfir, D., \& Nasser, F. (1997). Predicting teacher commitment. Teaching and Teacher Education, 13(4), 429-438.

Griffiths, M. (2006). The feminisation of teaching and the practice of teaching: Threat or opportunity? Educational Theory, 56(4), 387-405.

Guarino, C. M., Santibanez, L., \& Daley, G. A. (2006). Teacher recruitment and retention: A review of the recent empirical literature. Review of Educational Research, 76, 173-208.

Hackett, R. D., Lapierre, L. M., \& Hausdorf, P. A. (2001). Understanding the links between work commitments constructs. Journal of Vocational Behaviour, 58(3), 392-413.

Haywood, C., Popoviciu, L., \& Ghaill, M. M. (2005). Feminization and schooling: Re-masculinization, gendered reflexivity and boyness. Irish Journal of Sociology, 14(2), 193-212.

Holland, J. L. (1997). Making vocational choices: A theory of vocational personalities and work environments. Odessa, FL: Psychological Assessment Resources.

Hunt, K., Sweeting, H., Keoghan, M., \& Platt, S. (2006). Sex, gender role orientation, gender role attitudes and suicidal thoughts in three generations. Social Psychiatry and Psychiatric Epidemiology, 41(8), 641-647.

Ingersoll, R. (2001). Teacher turnover and teacher shortages: An organizational analysis. American Educational Research Journal, 38(3), 499-534.

Ingersoll, R. M., Peggy, R. M. I. N. A., Bobbitt, Q. S., Alsalam, N., Quinn, P., \& Bobbitt, S. (1997). Teacher professionalization and teacher commitment: A multilevel analysis. Washington, DC: National Centre for Education Statistics.

Jonathan, H., Thibeli, M., \& Darroux, C. (2013). Impact investigation of organisational commitment on intention to leave of public secondary school teachers in Tanzania. Developing Country Studies, 3(11), 78-91.

Kelleher, F. (2011). Women and the teaching profession: Exploring the feminisation debate. London: Commonwealth Secretariat and UNESCO.

Kitta, S., \& Fussy, D. (2013). Bottlenecks in preparation of quality teachers in Tanzania. Time Journals of Arts and Educational Research, 1(5), 29-38.

Klassen, R. M., \& Chiu, M. M. (2011). The occupational commitment and intention to quit of practicing and pre-service teachers: Influence of self-efficacy, job stress, and teaching context. Contemporary Educational Psychology, 36, 114-129.

Lippa, R. A. (1998). Gender-related individual differences and the structure of vocational interests: The importance of the people-things dimension. Journal of Personality and Social Psychology, 74(4), 996-1009.

Macdonald, D. (1999). Teacher attrition: A review of literature. Teaching and Teacher Education, 15(8), 835-848.

Maliki, A. E. (2013). Attitudes towards the teaching profession of students from the faculty of education, Niger Delta University. International Journal of Social Science Research, 1(1), 11-18.

Marsh, H. W., \& Myers, M. (1986). Masculinity, femininity, and androgyny: A methodological and theoretical critique. Sex Roles, 14(7-8), 397-430.

Meyer, J. P., Allen, N. J., \& Smith, C. A. (1993). Commitment to organizations and occupations: Extension and test of a three-component conceptualization. Journal of Applied Psychology, 78(4), 538-551. 
Mkumbo, K. A. K. (2012). Teachers' commitment to, and experiences of, the teaching profession in Tanzania: Findings of focus group research. International Education Studies, 5, 222-227.

Mulkeen, A., Chapman, D. W., Dejueghere, J. G., \& Leu, E. (2007). Recruiting, retaining, and retraining secondary school teachers and principals in Sub-Saharan Africa (No. 99). Washington, DC: World Bank Publications.

Mulkeen, A., \& Crowe-Taft, N. (2010). Teacher attrition in sub-Saharan Africa: The neglected dimension of the teacher supply challenge. France: UNESCO.

Reyes, P. (1990). Teachers' and their workplace: Commitment, performance and productivity. Newbury Park, CA: Sage.

Rice, A. (2006). Gender traits and normative/humanistic behaviour. Sociological Viewpoints, 22(2), 25-39.

Rosenholtz, S. J. (1989). Workplace conditions that affect teacher quality and commitment: Implications for teacher induction programs. The Elementary School Journal, 89, 421-439.

Rots, I., Aelterman, A., \& Devos, G. (2014). Teacher education graduates' choice (not) to enter the teaching profession: Does teacher education matter? European Journal of Teacher Education, 37(3), 279-294.

Rots, I., Aelterman, A., Devos, G., \& Vlerick, P. (2010). Teacher education and the choice to enter the teaching profession: A prospective Study. Teaching and Teacher Education, 26, 1619-1629.

Ruhland, S. K. (2001). Factors that influence the turnover and retention of Minnesota's technical college teachers. Journal of Vocational Education Research, 26(1), 56-76.

Ruhland, S. K. (2002). An examination of secondary business teachers' retention factors. In Paper presented at the annual meeting of the american educational research association. New Orleans, LA, April 1-5, 2002.

Songtao, F. (2000). Initial exploration of the phenomenon of the feminization of teachers. Chinese Education and Society, 33(4), 40-46.

Spence, J. T. (1993). Gender-related traits and gender ideology: Evidence for a multifactorial theory. Journal of Personality and Social Psychology, 64(4), 624-635.

Tait, M. (2008). Resilience as a contributor to novice teacher success, commitment, and retention. Teacher Education Quarterly, 35, 57-75.

Towse, P., Kent, D., Osaki, F., \& Kirua, N. (2002). Non-graduate teacher recruitment and retention: Some factors affecting effectiveness in Tanzania. Teaching and Teacher Education, 18, 637-652. doi:10. 1016/S0742-051X(02)00024-0.

Tschannen-Moran, M., \& Hoy, A. W. (2001). Teacher efficacy: Capturing an elusive construct. Teaching and Teacher Education, 17(7), 783-805.

Tungaraza, F. D. (2012). Undergraduate teachers' views of teaching as a career: Was teaching their choice? Journal of Adult Education, 19, 34-51.

Tyree, A. K. (1996). Conceptualizing and measuring commitment to high school teaching. The Journal of Educational Research, 89(5), 295-304.

United Republic of Tanzania. (2014). Basic statistics in education. Dar es Salaam: Ministry of Education and Vocational Training.

Ventieghem, W., Vermeersch, H., \& Van Houtte, M. (2014). Why gender disappeared from the gender gap: (Re)introducing gender identity theory to educational gender gap research. Social Psychology of Education, 17, 357-381.

Ware, H. W., \& Kitsantas, A. (2007). Teacher and collective efficacy beliefs as predictors of professional commitment. The Journal of Educational Research, 100(5), 303-310.

Watt, H. M. G., \& Richardson, P. W. (2007). Motivational factors influencing teaching as a career choice. Development and validation of FIT-Choice scale. The Journal of Experimental Education, 75(3), 167-202.

Watt, H. M. G., Richardson, P. W., \& Tysvaer, N. M. (2007). Profiles of beginning teachers' professional engagement and career development aspirations. In A. Berry, A. Clemans, \& A. Kostogriz (Eds.), Dimensions of professional learning: Professionalism, practice and identity. Rotterdam, The Netherlands: Sense.

Weisgram, E. S., Bigler, R. S., \& Liben, L. S. (2010). Gender, values, and occupational interest among children, adolescents and adults. Child Development, 81(3), 778-796. 
Ikupa Moses is a Ph.D. student at ICLON_Leiden University Graduate School of Teaching. She is an assistant lecturer at the Dar es Salaam University College of Education in the department of Educational Psychology and Curriculum Studies.

Wilfried F. Admiraal is full professor of Educational Sciences and chair of the research program Teaching and Teacher Learning of ICLON-Leiden University Graduate School of Teaching. He is teacher educator and researcher in the domain of teaching, teacher education and technology.

Amanda K. Berry is Professor of Education in the School of Education at Royal Melbourne Institute of Technology (RMIT) University in Melbourne, Australia. Amanda's research interests include teacher learning and development, science teaching and pedagogical content knowledge. 